\title{
Internationally Coordinated Emission Permit Policies: An Option for Withdrawers from the Kyoto Protocol?
}

\author{
Birgit Bednar-Friedl \\ Karl Farmer
}

\author{
CESIFO WORKING PAPER NO. 2764 \\ CATEGORY 10: ENERGY AND Climate ECONOMICS
}

August 2009

Presented At CESifo Venice Summer InStitute, July 2009

An electronic version of the paper may be downloaded

- from the SSRN website:

- from the RePEc website:

- from the CESifo website:

www.SSRN.com

Www.RePEc.org

www.CESifo-group.org/wp 


\title{
Internationally Coordinated Emission Permit Policies: An Option for Withdrawers from the Kyoto Protocol?
}

\begin{abstract}
This paper investigates the welfare costs of unilateral versus internationally coordinated emission permit policies in a two-country overlapping generations model with producer carbon emissions. We show that, for a net foreign debtor country, the domestic welfare costs of a unilateral domestic permit policy are larger than of an internationally coordinated policy if the world economy is dynamically efficient. From the perspective of a net foreign debtor country that has withdrawn from the Kyoto Protocol, an internationally coordinated permit policy is dominated by climate political inaction also in the post-Kyoto era since bearing the costs of foreign actionism is cheaper, in terms of welfare, than agreeing on international policy coordination - unless the world economy becomes dynamically inefficient.
\end{abstract}

JEL Code: Q52, Q54, D91.

Keywords: emission permit policies, trade, overlapping generations, welfare.

Birgit Bednar-Friedl

Department of Economics and Wegener

Center for Climate and Global Change

University of Graz

$8010 \mathrm{Graz}$

Austria

birgit.friedl@uni-graz.at
Karl Farmer

Department of Economics

University of Graz

Universitätsstr. 15

8010 Graz

Austria

karl.farmer@uni-graz.at

We would like to thank for discussions and inputs by conference participants of EAERE 2009 in Amsterdam (Netherlands), ECOMOD 2009 in Ottawa (Canada), WEAI 2009 in Vancouver (Canada) and the $10^{\text {th }}$ CESifo Summer Institute on "The Economics and Politics of Climate Change" in Venice (Italy). 


\section{Introduction}

After Australia's ratification of the Kyoto Protocol in 2008, the US was the only OECD country rejecting to ratify the Protocol. As is well known from the literature, the US withdrawal from this international agreement in 2001 has been informed by three major concerns: reduced international competitiveness, lack of developing countries participation (particularly China and India), and lagging public support for climate policy (see, e.g. Selin and VanDeveer, 2007; Weber and Peters, 2009). Despite the ongoing scepticism towards any international Post-Kyoto agreement, the Lieberman-Warner bill, also known as Americas's Climate Security Act (ACSA), passed the US Senate in late June 2009. This can be regarded as a first credible step towards domestic climate policy in the United States, and as a prerequisite for internationally coordinated climate policy in the future (Bang et al., 2007; Weber and Peters, 2009).

It is therefore of key relevance to global climate policy negotiations to identify arguments for the US that favor their participation in a Post-Kyoto agreement. Apart from concerns about competitiveness, developing countries' participation and public support, a useful, but often neglected, leverage for international climate policy is international trade (Weber and Peters, 2009): since the US is the world's largest importer and the second largest exporter, and since moreover the US is a large net foreign debtor to the world economy, any domestic and any foreign climate policy (at least of large trading partners like the European Union) has an effect on terms of trade, domestic and international prices, output (GDP), and thus the economy's welfare.

In this paper, we study in a stylized theoretical model the consequences of unilateral foreign climate policy for welfare of a country like the US which has not implemented domestic climate policy yet. Extending Ono's (2002) closed economy model, we use a two-good, two-country overlapping generations' model with producer greenhouse gas emissions and domestic permit systems. In order to be able to highlight the 
effects triggered by international trade in commodities as well as by the external balance of the involved countries, we model the countries as perfectly symmetric in terms of preferences and endowments, but slightly differentiated in terms of technology. The domestic country is assumed to be a net debtor while the foreign country is a net creditor to the world economy. Accordingly, the domestic country can be regarded as representing the US and the foreign country as the EU.

To single out the influence of the external balance of the involved countries and the dynamic (in)efficiency of the world economy, our analysis proceeds in two steps. We start by comparing the domestic welfare costs of a unilateral permit policy abroad to those of an internationally coordinated policy in order to see whether the domestic country is interested to reconsider its withdrawal by either deciding for unilateral permit reduction or agreeing on an internationally coordinated permit reduction. For that purpose, we derive the domestic and foreign welfare costs of climate policy, namely a unilateral reduction of the level of emission permits in either of the countries, following the approach taken for fiscal policy by Persson (1985). Secondly, we show from the perspective of a net foreign debtor country which has withdrawn from the Protocol under which conditions continual withdrawal is to be preferred to the consequences of climate political coordination.

Our paper contributes to the theoretical literature on the welfare consequences of unilateral and internationally coordinated climate policy by highlighting the role of a country's external balance (i.e., the net foreign asset position) and the dynamic (in)efficiency of the world economy. The early literature after the unilateral fiscal expansion in the United States in the 1980s aimed to understand the international consequences of unilateral fiscal policy among highly developed nations. This literature concluded that unilateral fiscal expansion reduces capital accumulation domestically and abroad (Lipton and Sachs, 1983) and that the terms of trade consequences depend on the external balance of the debt expanding country (Frenkel and Razin, 1986). As regards welfare effects of a unilateral expansion of public debt, the literature points to differences in the external balance and the dynamic 
(in)efficiency of the world economy. Persson (1985) finds that the domestic welfare costs are lower (or turn even to a welfare gain) when the more indebted country is a net foreign creditor given that the world economy is dynamically efficient. In particular, crowding out of private capital at home and abroad increases the worldwide real interest rate, which in turn affects the welfare of international debtors and creditors differently.

While many communalities can be found among the factors determining the welfare cost of fiscal policy and of unilateral climate policy, there is a remarkable difference regarding the impact on the terms of trade. Given that the countries are similar in terms of technology, fiscal policy does not affect the terms of trade of domestic exports and hence welfare is not affected through this channel (Farmer and Friedl, forthcoming). On the other hand, unilateral climate policy reduces production in the policy implementing country since greenhouse gas emissions are an indispensable production factor. The terms of trade of domestic exports improve and hence this positive effect on welfare counteracts the welfare cost through the output channel (in a static context, see Copeland and Taylor, 2005).

The main finding of this paper is that there is much welfare economic rationale for the climate political reluctance of net foreign debtor countries (like the United States) under dynamic efficiency (including the Golden Rule) of the world economy as well as for the effort put into Post-Kyoto negotiations on behalf of Kyoto complying countries (like the European Union). The disincentive provided by the higher welfare costs of a unilateral domestic climate policy compared to those of a unilateral climate policy abroad can contribute to the explanation of the withdrawal from the Kyoto Protocol. Secondly, for the Post-Kyoto era, internationally coordinated policies are still associated with higher domestic welfare costs than a unilateral foreign policy, despite the international interdependence of large economies. By a similar argument, the unilateral domestic policy is associated with higher welfare costs for Kyoto-complying countries than an internationally coordinated policy. Thus, Kyoto complying countries might have an welfare economic incentive to renegotiate with 
withdrawers to get them back on board.

This paper has five sections. In the next section we provide a description of the two-country, two-good model with nationally tradable emission permits. This will be followed by the derivation of the intertemporal equilibrium dynamics, existence and stability of steady state solutions in Section 3, and by the investigation of the steady state effects, caused by the reduction in the permit volume in one country, on the terms of trade, and on domestic and foreign capital accumulation. Section 4 is devoted to a thorough analysis and comparison of welfare costs of unilateral and internationally coordinated policies. Section 5 summarizes our results and concludes.

\section{The basic model}

Consider an infinite-horizon world economy of two countries, Home $H$ and Foreign $F$, which have the same population normalized to unity. Each country is composed of perfectly competitive firms and finitely lived consumers. The countries differ in their levels of public debt per capita, leading to diverging net foreign asset positions across countries. This assumption is essential for the emergence of international trade in a large open economy framework.

There are two tradeable goods, $x$ and $y^{*}$, and each country specializes in the production of a unique good, which can be used for the purpose of consumption in both countries as well as for investment. ${ }^{1}$ Both goods are produced by employing labor and capital, and both cause a flow of pollution. Households save in terms of internationally immobile capital and internationally mobile government bonds, where the supply of government bonds in each country is constant over time (as in Diamond, 1965). Without loss of generality, the rate of depreciation can be set at

\footnotetext{
${ }^{1}$ This assumption is a deviation of our model from the assumptions of the Heckscher-Ohlin model. Our model can be regarded as an OLG analoguous to Obstfeld's (1989) and Gosh's (1992) two-good, two-country ILA models.
} 
one, enabling investment of the current period to form next period's capital stock.

Regarding greenhouse gas emissions and climate policy, we follow the established approach in closed economy OLG models (Ono, 2002; Jouvet et al., 2005a,b; Bréchet et al., 2009) and focus on emissions from production that are regulated by an emissions permit trading system. Our model provides an open economy extension of these closed economy models and can thereby be used to analyze not only domestic effects but also international feedback effects of permit policies. We further assume that any production process causes pollution and that therefore each country implements a domestic emissions trading system with an exogenously set cap on domestic carbon emissions. ${ }^{2}$

\subsection{Firms and the permit markets}

Let the domestically produced good be $x$ and the foreign-produced good be $y^{\star}$, both in per capita terms (in the following, all foreign-country variables are denoted by a superscript asterisk). Countries Home and Foreign are assumed to have the same Cobb-Douglas constant-returns-to-scale production technology in per capita terms:

$$
x_{t}=M\left(k_{t}\right)^{\alpha_{K}}\left(p_{t}\right)^{\alpha_{P}}, \quad y_{t}^{*}=M\left(k_{t}^{*}\right)^{\alpha_{K}^{*}}\left(p_{t}^{*}\right)^{\alpha_{P}^{*}},
$$

where $M$ denotes a productivity scalar, $k_{t}\left(k_{t}^{\star}\right)$ and $p_{t}\left(p_{t}^{\star}\right)$ are respectively the capital-labor ratio and the pollution-labor ratio in $H(F){ }^{3}$

To incorporate unilateral and internationally coordinated climate policy, we assume

\footnotetext{
${ }^{2}$ Alternatively, one could model a global emissions trading system, which would lead to equal permit prices across countries. Another possibility would be to assume that goods consumed domestically (rather than those produced) fall under the permit trading scheme.

${ }^{3}$ Ono $(2002,77)$ shows how, by rescaling parameters, a production function exhibiting constant returns to scale with respect to labor and capital, and with emission intensity as a scaling factor, can be transformed into a three-factor constant returns to scale production function with labor, capital and pollution as inputs.
} 
that in each country and each period, the long-lived government sets an emissions cap and assigns corresponding emission permits to the production sector. This total number of emission permits is denoted by $S$ in Home and by $S^{\star}$ in Foreign. Following the specification of the permit market in Ono (2002), emission permits are initially distributed free of charge to the firms. If a firm's emissions exceed its allowance, then it buys emission permits in the domestic permit market, while for the opposite case it sells excess permits. International trade in emission permits is precluded.

In each period, firms in Home (and analogously for Foreign) choose $k$ and $p$ to maximize profit $\pi_{t}=x_{t}-q_{t} k_{t}-w_{t}+e_{t}\left(S-p_{t}\right)$, where $q_{t}\left(q_{t}^{\star}\right)$ is the rental price of capital, $w_{t}\left(w_{t}^{\star}\right)$ is the wage rate, and $e_{t}\left(e_{t}^{\star}\right)$ is the permit price in Home (Foreign). As described above, emission permits are traded in a perfectly competitive market. Since, moreover, firms rent capital and employ labor in perfect factor markets, the optimality conditions for maximizing profits in each period are given by:

$$
\begin{array}{lll}
q_{t}=\alpha_{K} \frac{x_{t}}{k_{t}}, & w_{t}=\left(1-\alpha_{K}-\alpha_{P}\right) x_{t}, & e_{t}=\alpha_{P} \frac{x_{t}}{p_{t}} \\
q_{t}^{*}=\alpha_{K}^{*} \frac{y_{t}^{*}}{k_{t}^{*}}, & w_{t}^{\star}=\left(1-\alpha_{K}^{*}-\alpha_{P}^{*}\right) y_{t}^{*}, & e_{t}^{\star}=\alpha_{P}^{*} \frac{y_{t}^{*}}{p_{t}^{*}} .
\end{array}
$$

Profit maximization implies that the firm's revenues net of the payments to production factors give a profit equal to the initial endowment of permits, $e_{t} S$. This profit is collected by the government and reimbursed to the young households. ${ }^{4}$

\subsection{Households and governments}

Each country is inhabited by identical consumers which live for two periods, one working and one retirement period. The representative consumer's intertemporal utility depends on consumption during the working period, composed of the consumption goods of both countries, $x_{t}^{1}$ and $y_{t}^{1}$, and consumption during the retirement period, $x_{t+1}^{2}$ and $y_{t+1}^{2}$. For simplicity, the representative households of countries $H$

\footnotetext{
${ }^{4}$ In essence, this particular modeling of the permit system guarantees that the subsidy is nondistortionary and that permits are not "grandfathered".
} 
and $F$ are assumed to have identical preferences across goods $(0<\zeta<1)$ and over time $(0<\beta<1)$ and are represented by a log-linear intertemporal utility function:

$$
\begin{gathered}
U_{t}=\zeta \ln x_{t}^{1}+(1-\zeta) \ln y_{t}^{1}+\beta\left[\zeta \ln x_{t+1}^{2}+(1-\zeta) \ln y_{t+1}^{2}\right], \\
U_{t}^{\star}=\zeta \ln x_{t}^{\star, 1}+(1-\zeta) \ln y_{t}^{\star, 1}+\beta\left[\zeta \ln x_{t+1}^{\star, 2}+(1-\zeta) \ln y_{t+1}^{\star, 2}\right] .
\end{gathered}
$$

Note that utility is independent of greenhouse gas emissions since households are short lived and it is reasonable to assume that they do not care for the benefits of delayed climate change in the distant future in response to reduced emissions today. Consequently, any change in lifetime utility of the households can be regarded as a welfare cost which defines a threshold value for the social benefit of delayed climate change.

In maximizing intertemporal utility (2), the domestic household is constrained by a budget constraint in each period of life. When young, wage income $w_{t}$, net of a lump-sum tax $\tau_{t}$ imposed by the national government, is spent on consumption of the domestic and the imported good, with $h_{t}$ denoting the terms of trade of Home (units of Foreign good per unit of Home good). Furthermore, for transferring income to their retirement period, young households save in terms of domestic capital $k_{t+1}$ and in terms of bonds of Home $b_{t+1}^{H}$ and of Foreign $b_{t+1}^{\star}$. From saving, the old household gains interest income, where $i_{t+1}$ and $i_{t+1}^{\star}$ denote the interest rates in Home and Foreign. When old, the household spends interest income and capital on consumption, again for the Home and Foreign good $\left(x_{t+1}^{2}\right.$ and $y_{t+1}^{2}$, respectively). Thus, the first period budget constraint for the domestic consumer is given by:

$$
x_{t}^{1}+\frac{1}{h_{t}} y_{t}^{1}+s_{t}=w_{t}-\tau_{t},
$$

where savings are defined as $s_{t} \equiv k_{t+1}+b_{t+1}^{H}+\left(1 / h_{t}\right) b_{t+1}^{\star, H}$. The corresponding budget constraint for the foreign consumer is:

$$
h_{t} x_{t}^{\star, 1}+y_{t}^{\star, 1}+s_{t}^{\star}=w_{t}^{\star}-\tau_{t}^{\star}
$$

where $s_{t}^{\star} \equiv k_{t+1}^{\star}+b_{t+1}^{\star, F}+h_{t} b_{t+1}^{F}$. After taking account of the no-arbitrage condition of the asset market in each country

$$
1+i_{t}=q_{t}, \quad 1+i_{t}^{*}=q_{t}^{*}, \quad \forall t,
$$


the second period budget constraint is given for the domestic consumer by

$$
x_{t+1}^{2}+\frac{1}{h_{t+1}} y_{t+1}^{2}=\left(1+i_{t+1}\right)\left[k_{t+1}+b_{t+1}^{H}\right]+\left(1+i_{t+1}^{\star}\right) \frac{1}{h_{t+1}} b_{t+1}^{\star, H},
$$

and for the foreign consumer by

$$
h_{t+1} x_{t+1}^{\star, 2}+y_{t+1}^{\star, 2}=\left(1+i_{t+1}^{\star}\right)\left(k_{t+1}^{\star}+b_{t+1}^{\star, F}\right)+h_{t+1}\left(1+i_{t+1}\right) b_{t+1}^{F} .
$$

Maximizing (2) subject to (3) and (5), and $\left(2^{\star}\right)$ subject to $\left(3^{\star}\right)$ and $\left(5^{\star}\right)$ gives the optimal consumption quantities as follows:

$$
\begin{aligned}
x_{t}^{1} & =\frac{\zeta}{1+\beta}\left(w_{t}-\tau_{t}\right), & x_{t+1}^{2} & =\frac{\beta \zeta}{1+\beta}\left(1+i_{t+1}\right)\left(w_{t}-\tau_{t}\right), \\
y_{t}^{1} & =\frac{1-\zeta}{1+\beta}\left(w_{t}-\tau_{t}\right) h_{t}, & y_{t+1}^{2} & =\frac{\beta(1-\zeta)}{1+\beta}\left(1+i_{t+1}\right)\left(w_{t}-\tau_{t}\right) h_{t+1}, \\
x_{t}^{*, 1} & =\frac{\zeta}{1+\beta} \frac{\left(w_{t}^{*}-\tau_{t}^{*}\right)}{h_{t}}, & x_{t+1}^{*, 2} & =\frac{\beta \zeta}{1+\beta}\left(1+i_{t+1}^{*}\right) \frac{\left(w_{t}^{*}-\tau_{t}^{*}\right)}{h_{t+1}}, \\
y_{t}^{*, 1} & =\frac{1-\zeta}{1+\beta}\left(w_{t}^{*}-\tau_{t}^{*}\right), & y_{t+1}^{*, 2} & =\frac{\beta(1-\zeta)}{1+\beta}\left(1+i_{t+1}^{*}\right)\left(w_{t}^{*}-\tau_{t}^{*}\right) .
\end{aligned}
$$

Utility maximizing domestic and foreign savings are then given by

$$
s_{t}=\sigma\left(w_{t}-\tau_{t}\right), \quad s_{t}^{*}=\sigma\left(w_{t}^{*}-\tau_{t}^{*}\right), \quad \sigma \equiv \frac{\beta}{(1+\beta)} .
$$

As mentioned above, the government runs a "constant-stock" fiscal policy and thus $b_{t+1}=b_{t}=b, \forall t$, and $b_{t+1}^{*}=b_{t}^{*}=b^{*}, \forall t$, respectively (as in Diamond, 1965). Then, market clearing for Home and Foreign bonds demands

$$
b=b_{t}^{H}+b_{t}^{F}, \quad \quad b^{*}=b_{t}^{*, H}+b_{t}^{*, F}, \quad \forall t .
$$

The budget constraints for Home and Foreign governments require that revenues from tax income and permit trading have to balance with interest payments to the bond holders:

$$
\tau_{t}+e_{t} S=i_{t} b, \quad \quad \tau_{t}^{*}+e_{t}^{*} S^{*}=i_{t}^{*} b^{*}, \quad \forall t
$$

\subsection{Market clearing and international trade}

Since government bonds are perfectly mobile across Home and Foreign,

$$
\left(1+i_{t+1}^{*}\right) \frac{h_{t}}{h_{t+1}}=\left(1+i_{t+1}\right), \quad \forall t .
$$


Clearing of Home's product market requires that domestic supply balances with domestic demand and exports $\left(x_{t}^{\star, 1}+x_{t}^{\star, 2}\right)$ :

$$
x_{t}=x_{t}^{1}+x_{t}^{2}+k_{t+1}+x_{t}^{*, 1}+x_{t}^{*, 2}, \quad \forall t,
$$

and for Foreign, that foreign supply balances with foreign demand and domestic imports $\left(y_{t}^{1}+y_{t}^{2}\right)$ :

$$
y_{t}^{*}=y_{t}^{*, 1}+y_{t}^{*, 2}+k_{t+1}^{*}+y_{t}^{1}+y_{t}^{2}, \quad \forall t,
$$

where the optimal consumption quantities are given from $(6)-\left(7^{\star}\right)$.

Clearing of the world asset market requires the supply of savings to be equal to the demand for savings (from $(3),\left(3^{\star}\right)$, and $\left.(9)\right)$ :

$$
s_{t}+\frac{1}{h_{t}} s_{t}^{*}=k_{t+1}+b+\frac{1}{h_{t}}\left[k_{t+1}^{*}+b^{*}\right], \quad \forall t .
$$

This equation thus relates the terms of trade movements to capital accumulation and to the levels of domestic and foreign debt. Rearranging gives the following

relationship between Home's terms of trade and the net foreign asset positions of Foreign $\left(\phi_{t+1}^{*}\right)$ and Home $\left(\phi_{t+1}\right)$ :

$$
h_{t}=-\frac{k_{t+1}^{*}+b^{*}-s_{t}^{*}}{k_{t+1}+b-s_{t}} \equiv-\frac{\phi_{t+1}^{*}}{\phi_{t+1}}, \quad \forall t .
$$

Since $h_{t}>0$, either $\phi_{t+1}>0$ and consequently $\phi_{t+1}^{*}<0$, Home is a net debtor and Foreign a net creditor, or $\phi_{t+1}<0$ and $\phi_{t+1}^{*}>0$ which means that Home is a net creditor and Foreign a net debtor.

\section{Steady state effects of unilateral or internation- ally coordinated permit policy}

In this section, we first present the dynamic equations describing the intertemporal equilibrium of our two-country, two-good model before deriving the steady state and the effects of unilateral permit polices on the steady state. 


\subsection{Intertemporal equilibrium dynamics}

Acknowledging the market clearing for the permit market in Home $\left(p_{t}=S, \forall t\right)$, and substituting for the firm's first order conditions (1) yields an expression for $s_{t}$ which depends only on $k_{t}$ and exogenously given parameters, and similarly for $s_{t}^{*}$. By inserting these optimal savings functions into the international asset market clearing condition (13), we obtain the second equation of motion:

$$
h_{t} k_{t+1}+k_{t+1}^{*}=h_{t}\left[\sigma_{0}\left(k_{t}\right)^{\alpha_{K}}-b\left(\sigma i_{t}+1\right)\right]+\sigma_{0}^{*}\left(k_{t}^{*}\right)^{\alpha_{K}}-b^{*}\left(\sigma i_{t}^{*}+1\right),
$$

where $\sigma_{0} \equiv\left(1-\alpha_{K}\right) \sigma M S^{\alpha_{P}}$ and $\sigma_{0}^{*} \equiv\left(1-\alpha_{K}^{*}\right) \sigma M\left(S^{*}\right)^{\alpha_{P}^{*}}$.

Multiplying the national product market clearing condition of Home (12) by $h_{t}$ and the one of Foreign $\left(12^{\star}\right)$ by $\zeta /(1-\zeta)$, inserting optimal consumptions of households in Home and Foreign $(6)-\left(7^{\star}\right)$, and subtracting the second from the first gives the combined product market clearing condition as third law of motion:

$$
h_{t} k_{t+1}-\frac{\zeta}{(1-\zeta)} k_{t+1}^{*}=h_{t} M\left(k_{t}\right)^{\alpha_{K}}(S)^{\alpha_{P}}-\frac{\zeta}{(1-\zeta)} M\left(k_{t}^{*}\right)^{\alpha_{K}^{*}}\left(S^{*}\right)^{\alpha_{P}^{*}} .
$$

Considering the no-arbitrage conditions for national asset markets (4), and the firms' first order conditions $(1)$ and $\left(1^{\star}\right)$ in the international interest parity condition (11), the equation of motion of the terms of trade follows

$$
h_{t+1}=h_{t} \frac{\left(1+i_{t+1}^{*}\right)}{\left(1+i_{t+1}\right)}=h_{t} \frac{\alpha_{K}^{*}\left(k_{t+1}^{*}\right)^{\alpha_{K}^{*}-1}\left(S^{*}\right)^{\alpha_{P}^{*}}}{\alpha_{K}\left(k_{t+1}\right)^{\alpha_{K}-1}(S)^{\alpha_{P}}} .
$$

The dynamic system for the terms of trade, $h_{t}$, and for the (per capita) capital stocks in Home and Foreign $\left(k_{t+1}\right.$ and $k_{t+1}^{*}$ respectively) are thus described by Equations (14), (15), and (16).

\subsection{Characterisation of steady states}

A steady state of the discrete dynamical system (14)-(16) is defined by

$$
\left(h, k, k^{*}\right)=\left(h_{t}, k_{t}, k_{t}^{*}\right)=\left(h_{t+1}, k_{t+1}, k_{t+1}^{*}\right) .
$$


Under the presumption of parameter sets which ensure the existence of at least one non-trivial steady state, these dynamic equations can be reduced to a system of three equations which determine the endogenous variables $k, h$ and $k^{*}$. According to (14), the geometrical locus of all pairs $(k, h)$ which assure international asset market clearing will be labeled, in accordance with Zee $(1987,613)$, as the $K K$-curve:

$$
h=-\frac{\phi^{*}}{\phi} \equiv-\frac{\left[k^{*}-M\left(k^{*}\right)^{\alpha_{K}^{*}-1}\left(S^{*}\right)^{\alpha_{P}^{*}} \sigma\left(\left(1-\alpha_{K}^{*}\right) k^{*}-b^{*} \alpha_{K}^{*}\right)+(1-\sigma) b^{*}\right]}{\left[k-M(k)^{\alpha_{K}-1}(S)^{\alpha_{P}} \sigma\left(\left(1-\alpha_{K}\right) k-b \alpha_{K}\right)+(1-\sigma) b\right]}
$$

and, following from (15), the equilibrium condition for the combined product market and will be labeled $G G$-curve:

$$
h=\frac{\zeta}{(1-\zeta)} \frac{H^{*}}{H} \equiv \frac{\zeta}{(1-\zeta)} \frac{\left[M\left(k^{*}\right)^{\alpha_{K}^{*}}\left(S^{*}\right)^{\alpha_{P}^{*}}-k^{*}\right]}{\left[M(k)^{\alpha_{K}}(S)^{\alpha_{P}}-k\right]},
$$

where, from (16),

$$
k^{*}=\left(\frac{\alpha_{K}^{*}}{\alpha_{K}}\right)^{\frac{1}{1-\alpha_{K}^{*}}}\left(\frac{\left(S^{*}\right)^{\alpha_{P}^{*}}}{(S)^{\alpha_{P}}}\right)^{\frac{1}{1-\alpha_{K}^{*}}}(k)^{\epsilon}, \quad \epsilon \equiv \frac{1-\alpha_{K}}{1-\alpha_{K}^{*}} .
$$
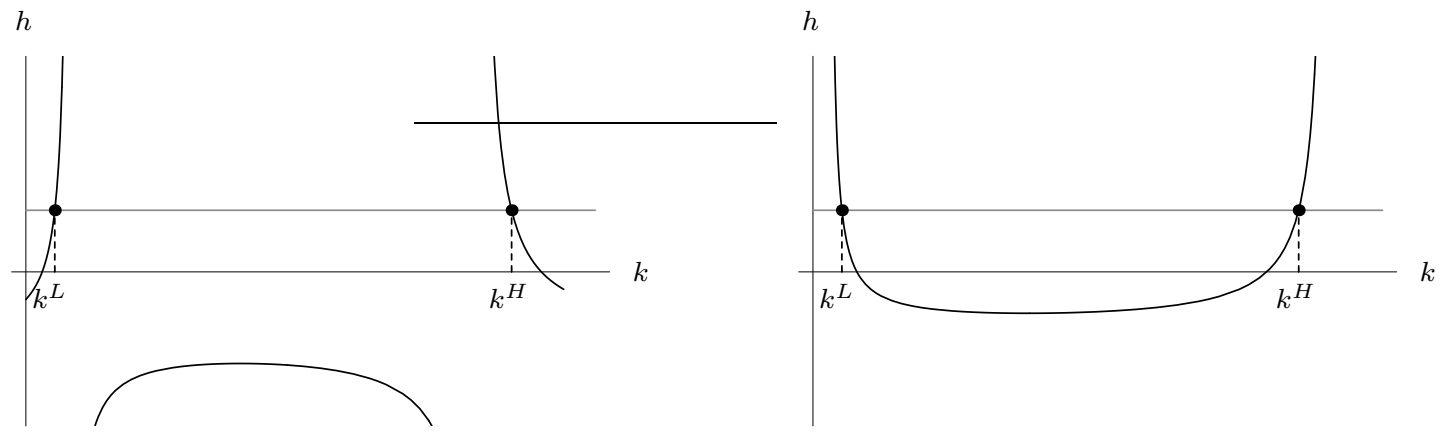

Figure 1: The $K K$-curves (black) and $G G$-curves (gray) for $\phi>0$ (left), and $\phi<0$ (right).

A steady state general equilibrium occurs when the $K K$-curve and the $G G$-curve intersect in the first quadrant. For identical production elasticities across countries, $\alpha_{K}=\alpha_{K}^{*}$ and $\alpha_{P}=\alpha_{P}^{*}$, Figure 1 depicts two typical configurations of $K K$ - and $G G$-curves. Inspection of the slopes reveals that the $K K$-curve is $\mathrm{U}$-shaped if $\phi<0$ and inverted $\mathrm{U}$-shaped if $\phi>0$. The $G G$-curve is due to assumption of identical technologies horizontal. The existence of two non-trivial steady states, $k^{L}$ and $k^{H}$, is proven in Appendix A.1. 
Being assured of the existence of two distinct steady-state solutions, the next step is to investigate the local stability of the two steady states. For the parameter sets underlying Figure 1, the calculation of the Jacobian matrix of the dynamic system in the two steady states indicates that in the steady state with the lower capital intensity $\left(k^{L}\right)$ two eigenvalues are larger and one is less than unity, while in the steady state with the higher capital intensity $\left(k^{H}\right)$ one eigenvalue is larger and two are less than unity (for the formal proof, see Farmer et al., 2008, 29-31). Thus, the former steady state is saddle path unstable while the latter is saddle path stable. In

Figure 1, this stable steady state associated with the higher capital intensity $k^{H}$ can be found as the second point of intersection of the GG- and KK-curve (for both cases). Due to the algebraic complexity of the Jacobian of the equilibrium dynamics around the steady states, the stability of the steady states can be proven only for small differences between $\alpha_{K}$ and $\alpha_{K}^{*}$ (see Appendix A.2).

\subsection{Steady state effects of different permit policies}

Knowing that the steady state associated with $k^{H}$ qualifies as being locally stable, we can now turn to the investigation of the long-run effects of a unilateral permit reduction on the main variables of our model. To pursue this objective, we assume that either Home implements a more stringent permit policy $(\mathrm{d} S<0)$ while the permit policy of Foreign remains unchanged at $S^{*}$. Alternatively, Foreign could implement a permit policy $\left(\mathrm{d} S^{\star}<0\right)$ while Home's permit policy remains unchanged. As a third case, we investigate the steady state effects of an internationally coordinated permit policy in which both countries implement permit policies, assuming that they reduce in total as much as one country would reduce unilaterally. We further assume that the shock is unannounced and permanent such that the households and firms cannot act anticipatory prior to the shock (e.g., by adjusting their saving decision). Furthermore, to keep the analysis tractable, we assume from now on equal production elasticities countries, i.e. $\alpha_{K}=\alpha_{K}^{*}$ and $\alpha_{P}=\alpha_{P}^{*}$. 
To determine the effects of a marginal unilateral reduction of emission permits on the three dynamic variables, we totally differentiate (17), (18), and (19), with respect to $S$ and $S^{*}$. The comparative steady state effects of unilateral permit policies are given in Proposition 1.

Proposition 1 Let $\alpha_{K}=\alpha_{K}^{*}$ and $\alpha_{P}=\alpha_{P}^{*}$. An infinitesimal change of $S$ and/or $S^{*}$ leads to a shift of the equilibrium along the gradient given by

$$
\left[\begin{array}{c}
\mathrm{d} h \\
\mathrm{~d} k \\
\mathrm{~d} k^{*}
\end{array}\right]=\frac{\alpha_{P}}{\left(1-\alpha_{K}\right)}\left[\begin{array}{c}
-h \\
(1+\gamma) k \\
\gamma k^{*}
\end{array}\right] \frac{\mathrm{d} S}{S}+\frac{\alpha_{P}}{\left(1-\alpha_{K}\right)}\left[\begin{array}{c}
h \\
\gamma^{*} k \\
\left(1+\gamma^{*}\right) k^{*}
\end{array}\right] \frac{\mathrm{d} S^{*}}{S^{*}}
$$

where $\gamma \equiv \frac{\zeta b(1+\sigma i)}{k\left(1-\lambda_{3}\right)}, \gamma^{*} \equiv \frac{(1-\zeta) b^{*}(1+\sigma i)}{k^{*}\left(1-\lambda_{3}\right)}, \lambda_{3} \equiv(1+i) \sigma\left(1-\alpha_{K}\right)\left[1+\frac{\vartheta}{k}\right]$, $\vartheta \equiv\left(\zeta b+(1-\zeta) b^{*}\left(S / S^{*}\right)^{\alpha_{P} /\left(1-\alpha_{K}\right)}\right)$, and $\gamma>0, \gamma^{*}>0$ for $k=k^{H}$.

Proof 1 See Appendix A.3.

For $k=k^{H}$, and similar technologies across countries, Proposition 1 states that a unilateral permit policy leads to a decline in both the equilibrium values of $k$ and $k^{\star}$, but with a stronger domestic effect than abroad $\left(1+\gamma>\gamma^{*}\right)$. Thus, in contrast to a closed economy, international trade causes a spillover effect on foreign capital accumulation - the permit reducing country crowds out capital not only domestically but also abroad. The reason why crowding out occurs in both countries is that interest parity across countries is required by (19): Since the decline in the domestic capital stock increases the domestic interest rate, the foreign interest rate has to increase too which leads to a decline in the foreign capital stock. Furthermore, and due to the assumption of two large economies, the permit reducing country experiences an improvement in her terms of trade because domestic prices rise relative to foreign prices. ${ }^{5}$

\footnotetext{
${ }^{5}$ This can also be seen from (18) where a reduction in $S$ leads to an improvement of the terms of trade. Thus, the foreign good in units of the domestic good becomes cheaper.
} 
Corollary 1 applies Proposition 1 to the case of internationally coordinated climate policy. To be able to compare the coordinated to the unilateral policies, we assume that the total level of permit reduction is fixed worldwide and that under an internationally coordinated policy Home reduced at a share of $\mathrm{d} \bar{S}=\delta \mathrm{d} S$ and Foreign at a share of $\mathrm{d} \bar{S}^{\star}=(1-\delta) \mathrm{d} S^{\star}$. As stated formally in Corollary 1, under the assumption that both countries implement an equally strong permit reduction (i.e. $\mathrm{d} S=\mathrm{d} S^{\star}$ and $\delta=1 / 2$ ), the terms of trade effect vanishes and the capital stock effects are symmetric for both countries.

Corollary 1 Let $\alpha_{K}=\alpha_{K}^{*}$ and $\alpha_{P}=\alpha_{P}^{*}$ and $S=S^{*}$. Suppose that both countries implement a permit policy such that $\mathrm{d} \bar{S}=\delta \mathrm{d} S, \mathrm{~d} \bar{S}^{\star}=(1-\delta) \mathrm{d} S^{\star}$, where $\mathrm{d} S=\mathrm{d} S^{\star}$, $0<\delta<1$ and $\delta=1 / 2$. A simultaneously infinitesimal change of $S$ and $S^{*}$ leads to a shift of the equilibrium along the gradient given by

$$
\left[\begin{array}{c}
\mathrm{d} h \\
\mathrm{~d} k \\
\mathrm{~d} k^{*}
\end{array}\right]=\frac{\alpha_{P}}{\left(1-\alpha_{K}\right)}\left[\begin{array}{c}
0 \\
\left(1+\gamma+\gamma^{*}\right) k \\
\left(1+\gamma+\gamma^{*}\right) k^{*}
\end{array}\right] \frac{\delta \mathrm{d} S}{S} .
$$

Knowing that a unilateral policy leads both to a positive domestic (and a negative foreign) terms of trade effect and to a negative capital stock effect while an internationally coordinated policy impacts only on capital accumulation, the next step is to investigate the welfare costs of these steady state effects. The purpose of the next section is is to investigate the welfare consequences of unilateral versus internationally coordinated permit policies taking account of the net foreign asset position of the countries and the dynamic efficiency (inefficiency) of the world economy.

\section{The welfare cost of different permit policies}

The welfare consequences of permit policies are determined by the effect of adjustments in the terms of trade and capital stocks on lifetime utility as defined by (2) 
and $\left(2^{\star}\right)$. Since both utility functions incorporate only consumption of goods but not environmental quality, any decline in utility can be regarded as the welfare cost of a permit policy. The higher the welfare cost of unilateral permit policy the lower is the incentive of a country to perform a unilateral reduction of emission permits or to agree on an internationally coordinated permit policy.

To analyze the welfare costs of unilateral versus internationally coordinated permit policies, we proceed in the following way. First, we derive the welfare costs of unilateral permit policies for the domestic economy, i.e. of a unilateral domestic or a unilateral foreign permit policy. Secondly, we compare the domestic welfare costs of a unilateral permit policy and an internationally coordinated permit policy. As in the previous chapter, our definition of an internationally coordinated policy is that both countries implement policies, and that they reduce in total as much as one country would reduce unilaterally.

\subsection{Derivation of welfare changes}

To derive the domestic steady state welfare effects of a reduction in $S$ and $S^{\star}$,

we define the indirect intertemporal utility function of Home as $U\left(x^{1}, y^{1}, x^{2}, y^{2}\right) \equiv$ $V(w-\tau, 1+i, h)$ (from (2) substituting for optimal consumption levels (6)-(7)) and differentiate it with respect to the dynamic variables. Using the first order conditions of Home's utility maximization problem, the change in domestic welfare 
due to an infinitesimal reduction in Home's permit volume $S$ is given by: ${ }^{6}$

$$
\begin{aligned}
\frac{\mathrm{d} V}{\mathrm{~d} S}=\frac{(1+\beta)}{(w-\tau)}\{ & {\left[\frac{\partial(w-\tau)}{\partial k}+\frac{s}{(1+i)} \frac{\partial(1+i)}{\partial k}\right] \frac{\mathrm{d} k}{\mathrm{~d} S}+} \\
& \left.+\left[(1-\zeta) \frac{(w-\tau)}{h}\right] \frac{\mathrm{d} h}{\mathrm{~d} S}+\left[\frac{\partial(w-\tau)}{\partial S}+\frac{s}{(1+i)} \frac{\partial(1+i)}{\partial S}\right]\right\},
\end{aligned}
$$

and, proceeding similarly for Foreign's policy, the change in domestic welfare is given by

$$
\frac{\mathrm{d} V}{\mathrm{~d} S^{\star}}=\frac{(1+\beta)}{(w-\tau)}\left\{\left[\frac{\partial(w-\tau)}{\partial k}+\frac{s}{(1+i)} \frac{\partial(1+i)}{\partial k}\right] \frac{\mathrm{d} k}{\mathrm{~d} S^{\star}}+\left[(1-\zeta) \frac{(w-\tau)}{h}\right] \frac{\mathrm{d} h}{\mathrm{~d} S^{\star}}\right\} .
$$

The change in domestic welfare caused by an infinitesimal unilateral domestic permit reduction $\mathrm{d} V / \mathrm{d} S$ incorporates both indirect effects of a change in $S$ on the capital stock and on the terms of trade as well as direct effects of a change in $S$ on factor prices $(w-\tau)$ and $(1+i)$. Welfare in the non-reducing country $\mathrm{d} V / \mathrm{d} S^{\star}$ is affected only by the indirect effects of a reduction in $S^{\star}$ on the capital stock and the terms of trade. Regarding the terms of trade effect, we know from the previous section that the permit reducing country experiences a terms of trade improvement while the non-reducing country is affected by a terms of trade deterioration $(\mathrm{d} h / \mathrm{d} S>0$ and $\left.\mathrm{d} h / \mathrm{d} S^{*}<0\right)$, leading to a welfare improvement in the reducing and to a welfare deterioration in the non-reducing country. ${ }^{7}$

To determine the sign of the domestic welfare response caused by unilateral domestic and foreign permit policies, we make again use of the assumption of similar

\footnotetext{
${ }^{6}$ To be more precise, the equality sign in (20) and (21) should be substituted for $\approx$ because of the welfare costs of a unilateral reduction of $H$ 's permit volume $V\left(S+\mathrm{d} S, S^{\star}\right)-V\left(S, S^{\star}\right)$ are exactly equal to

$$
\frac{\partial V\left(S, S^{\star}\right)}{\partial S} \mathrm{~d} S+1 / 2 \frac{\partial^{2} V\left(S, S^{\star}\right)}{\partial S^{2}}(\mathrm{~d} S)^{2}+R_{3}\left(S+\mathrm{d} S, S^{\star}\right),
$$

whereby $R_{3}\left(S+\mathrm{d} S, S^{\star}\right)$ is the remainder after two terms according to Taylor's formula (see Sydsaeter et al., 2005, 77-78). Obviously, we are satisfied with a linear approximation, assuming $\mathrm{d} S$ being infinitesimally small.

${ }^{7}$ In a closed economy context, this type of effect was called by Meade (1952) 'pecuniary externality' to describe a situation where the changed activity level of one agent affects the financial circumstances of another agent due to a change in prices (for a discussion, see Baumol and Oates, 1988, 14-16; 29-30).
} 
technologies across countries.

Proposition 2 Let $\alpha_{K}=\alpha_{K}^{*}$ and $\alpha_{P}=\alpha_{P}^{*}$. Acknowledging that $(w-\tau)=$ $\left(1-\alpha_{K}\right) / \alpha_{K}(1+i) k-i b$ and $\phi=k+b-s$, the change in domestic welfare of an infinitesimal unilateral permit reduction in Home, $S$, is then given by

$$
\frac{\mathrm{d} V}{\mathrm{~d} S}=\frac{(1+\beta)}{(w-\tau)} \frac{\alpha_{P}}{S}\left\{\gamma[i(k+b)+\phi]+\zeta \frac{(1+i) k}{\alpha_{K}}+(1-\zeta) \frac{i b}{\left(1-\alpha_{K}\right)}\right\},
$$

and of a foreign policy, after acknowledging that $i=i^{\star}$ in the steady state:

$$
\frac{\mathrm{d} V}{\mathrm{~d} S^{\star}}=\frac{(1+\beta)}{(w-\tau)} \frac{\alpha_{P}}{S^{\star}}\left\{\gamma^{\star}[i(k+b)+\phi]+(1-\zeta) \frac{(1+i) k}{\alpha_{K}}-(1-\zeta) \frac{i b}{\left(1-\alpha_{K}\right)}\right\} .
$$

Depending on the signs of $i$ and $\phi$, three cases emerge:

(i) For $\phi>0$ (Home is a net foreign debtor), $\mathrm{d} V / \mathrm{d} S>0 \Longleftrightarrow i \geq 0$ and $\mathrm{d} V / \mathrm{d} S^{\star}>$ $0 \Longleftrightarrow i=0$, while for $i>0$ the sign of $\mathrm{d} V / \mathrm{d} S^{\star}$ is ambiguous.

(ii) For $\phi<0$ (Home is a net foreign creditor) and $i=0, \mathrm{~d} V / \mathrm{d} S>0 \Longleftrightarrow$ $\gamma \phi+\zeta k / \alpha_{K}>0$ and $\mathrm{d} V / \mathrm{d} S^{\star}>0 \Longleftrightarrow \gamma^{*} \phi+(1-\zeta) k / \alpha_{K}>0$, while for $i>0$ the signs of $\mathrm{d} V / \mathrm{d} S$ and of $\mathrm{d} V / \mathrm{d} S^{\star}$ are ambiguous.

(iii) For $i<0$, the signs of $\mathrm{d} V / \mathrm{d} S$ and $\mathrm{d} V / \mathrm{d} S^{\star}$ are ambiguous.

Proof 2 See Appendix A.4

Proposition 2 illustrates the importance of the net foreign asset position $(\phi)$ and the dynamic (in)efficiency of the world economy $\left(i=i^{*} \geq 0\right.$ or $\left.i=i^{*}<0\right)$. Depending on whether the permit reducing country is a net debtor or a net creditor to the world economy, and on whether the steady state interest rate is positive (dynamic efficiency), zero (Golden Rule), or negative (dynamic inefficiency), the terms in (22)-(23) are either unidirectional and hence the welfare cost of a permit reduction are certainly positive, or some of the terms are positive while others are negative, leading to an ambiguous welfare effect. 
For the dynamically efficient case $(i>0)$ or the Golden Rule $(i=0)$ where Home is a net foreign debtor $(\phi>0)$, the net welfare effect of a domestic permit reduction is unambiguously negative. For the opposite case where Home is a net foreign creditor $(\phi<0)$, however, the net welfare effect can be signed unambiguously negative only for the case of the Golden Rule, as a special case of dynamic efficiency where $i=0$, and if $|\gamma \phi|$ is smaller than $\zeta k / \alpha_{K}$. Thus, in both cases (i) and (ii) a unilateral reduction of the permit level leads to welfare costs that have to be outweighed by environmental benefits for the policy to be approved by the social planner. If in contrast the interest rate were negative in the initial steady state (dynamic inefficiency) as in case (iii), we cannot rule out the case that $\mathrm{d} V / \mathrm{d} S$ and $\mathrm{d} V / \mathrm{d} S^{\star}$ becomes negative and hence welfare improves when the permit level is reduced.

Similarly, the domestic welfare effect of a unilateral permit reduction abroad is unambiguously negative if the Golden Rule applies, regardless of whether the domestic economy is a net debtor or a net creditor to the world economy. Under dynamic efficiency of the world economy, and also under dynamic efficiency, positive and negative effects prevail such that the domestic welfare effect of a unilateral policy in either of the countries is ambiguous. We turn next to a comparison of the domestic welfare cost of a unilateral domestic versus an internationally coordinated permit policy.

\subsection{Comparison of welfare costs of a unilateral domestic and an internationally coordinated permit policy}

To understand why some net foreign debtor countries have withdrawn from the Kyoto Protocol, we compare the welfare costs of a unilateral permit reduction policy and of an internationally coordinated policy. To be able to compare those two policies, we assume that the total level of permit reduction is fixed worldwide and that either both countries reduce (at a share of $0<\delta<1$ for Home and $(1-\delta)$ for Foreign, respectively), or one country reduces unilaterally (such that either $\delta=1$ 
or 0 otherwise). Thus, the welfare cost of the unilateral domestic permit policy is defined as

$$
V\left(S+\mathrm{d} S, S^{\star}\right)-V\left(S, S^{\star}\right)=\frac{\mathrm{d} V}{\mathrm{~d} S} \mathrm{~d} S,
$$

whereas the welfare cost of the harmonized permit policy is

$$
V\left(S+\delta \mathrm{d} S, S^{\star}+(1-\delta) \mathrm{d} S^{\star}\right)-V\left(S, S^{\star}\right)=\delta \frac{\mathrm{d} V}{\mathrm{~d} S} \mathrm{~d} S+(1-\delta) \frac{\mathrm{d} V}{\mathrm{~d} S^{\star}} \mathrm{d} S^{\star} .
$$

Assuming that both countries implement equally stringent unilateral permit policies and hence $\delta=(1-\delta)=1 / 2, S=S^{\star}$ and $\mathrm{d} S=\mathrm{d} S^{\star}$, the welfare cost of the internationally coordinated permit policy reduces to

$$
\begin{aligned}
V\left(S+\frac{\mathrm{d} S}{2}, S^{\star}+\frac{\mathrm{d} S^{\star}}{2}\right)-V\left(S, S^{\star}\right) & = \\
& =\frac{1+\beta}{(w-\tau)} \frac{\alpha_{P}}{S}\left\{\left[\gamma+\gamma^{*}\right][i(k+b)+\phi]+\frac{(1+i) k}{\alpha_{K}}\right\} \frac{\mathrm{d} S}{2} .
\end{aligned}
$$

Note that when both countries reduce their permit levels equally, the terms of trade effect on welfare, which contributes positively to welfare in case of a unilateral domestic policy (and negatively in case of a unilateral foreign policy), vanishes. What remains are the welfare reducing effects through the impact on the capital stock.

Thus, when comparing (24), taking account of $(22)$, with $\left(25^{\prime}\right)$ it is not straight forward to see which policy leads to higher welfare costs. While the unilateral domestic policy leads to, according to Proposition 1 and Corollary 1, higher reductions in domestic capital accumulation compared to the internationally coordinated policy, the positive terms of trade effect on welfare is present only under the unilateral but not under the internationally coordinated policy. Furthermore, knowing that the net foreign asset position of a country determines whether her unilateral permit policy $\mathrm{d} S<0$ causes larger (smaller) domestic than foreign welfare costs, the question arises whether this relationship pertains also when comparing the domestic welfare costs of a unilateral domestic and of an internationally coordinated permit policy.

Proposition 3 Let $\alpha_{K}=\alpha_{K}^{\star}, \alpha_{P}=\alpha_{P}^{\star}, \zeta=(1-\zeta), S=S^{*}$. Suppose that either Home implements a permit policy $\mathrm{d} S<0$ or both countries implement a permit 
policy such that $\mathrm{d} \bar{S}=\delta \mathrm{d} S, \mathrm{~d} \bar{S}^{\star}=(1-\delta) \mathrm{d} S^{\star}$, where $\mathrm{d} S=\mathrm{d} S^{\star}, 0<\delta<1$ and $\delta=1 / 2$. Then, the difference in the domestic welfare costs of a domestic unilateral permit policy and an internationally coordinated permit policy is given by

$$
\begin{aligned}
V\left(S+\mathrm{d} S, S^{\star}\right)-V & \left(S+\frac{\mathrm{d} S}{2}, S^{\star}+\frac{\mathrm{d} S^{\star}}{2}\right)= \\
& =\frac{1+\beta}{(w-\tau)} \frac{\alpha_{P}}{S}\left\{\left[\gamma-\gamma^{*}\right][i(k+b)+\phi]+\frac{i b}{\left(1-\alpha_{K}\right)}\right\} \frac{\mathrm{d} S}{2} .
\end{aligned}
$$

Depending on the signs of $i$ and $\phi$, three cases emerge:

(i) For $i \geq 0$ (dynamic efficiency) and $\phi>0, \quad V\left(S+\mathrm{d} S, S^{\star}\right)<V\left(S+\frac{\mathrm{d} S}{2}, S^{\star}+\frac{\mathrm{d} S^{\star}}{2}\right)$.

(ii) For $i=i^{\star}=0$ (Golden Rule) and $\phi<0, \quad V\left(S+\mathrm{d} S, S^{\star}\right)<V\left(S+\frac{\mathrm{d} S}{2}, S^{\star}+\frac{\mathrm{d} S^{\star}}{2}\right)$.

(iii) For $i<0$ (dynamic inefficiency), the sign of $V\left(S+\mathrm{d} S, S^{\star}\right)-V\left(S+\frac{\mathrm{d} S}{2}, S^{\star}+\frac{\mathrm{d} S^{\star}}{2}\right)$ is ambiguous.

Proof 3 To derive (26), we subtract (25') from (24) and utilize (23) and (22).

Case $i$ : Since $\phi>0$ and $\phi=(1+\sigma i)(1-\zeta)\left(b-b^{*}\right), b>b^{*}$ which implies that $\gamma-\gamma^{*}=\frac{(1+\sigma i) \zeta\left(b-b^{*}\right)}{k\left(1-\lambda_{3}\right)}>0$. With $i>0, V\left(S+\mathrm{d} S, S^{\star}\right)<V\left(S+\frac{\mathrm{d} S}{2}, S^{\star}+\frac{\mathrm{d} S^{\star}}{2}\right)$. Case ii: Since $\phi<0, b<b^{*}$ and hence $\gamma<\gamma^{*}$. With $i=0, V\left(S+\mathrm{d} S, S^{\star}\right)<$ $V\left(S+\frac{\mathrm{d} S}{2}, S^{\star}+\frac{\mathrm{d} S^{\star}}{2}\right)$.

Case iii: Since $i<0$, the sign of $V\left(S+\mathrm{d} S, S^{\star}\right)-V\left(S+\frac{\mathrm{d} S}{2}, S^{\star}+\frac{\mathrm{d} S^{\star}}{2}\right)$ is ambiguous.

Thus, Proposition 3 demonstrates that irrespective of the net foreign asset position of a country, it is beneficial for Home in terms of her welfare costs to achieve an internationally coordinated permit policy instead of a unilateral domestic, given that in case of a net creditor country the Golden Rule applies. If, in contrast, dynamic inefficiency holds in the initial steady state, the sign of $V\left(S+\frac{\mathrm{d} S}{2}, S^{\star}+\frac{\mathrm{d} S^{\star}}{2}\right)-$ $V\left(S, S^{\star}+\mathrm{d} S^{\star}\right)$ is ambiguous. Eventually, Home's unilateral policy might thus lead to lower domestic welfare losses than a harmonized policy. For numerical values of 
policy parameters which imply that Home is a net foreign creditor like the European Union and that the world economy is either dynamically efficient or inefficient, the welfare costs of unilateral domestic permit policy can become lower than the welfare costs of internationally coordinated permit policy. Three main channels cause this counter-intuitive result: compared to the unilateral domestic policy, the terms of trade effect of an internationally coordinated policy vanishes; secondly, the crowding out effect on domestic capital accumulation is ameliorated (and a considerable fraction is shifted abroad); and thirdly, the permit prices rise equally in both countries rather than the price differential caused by a unilateral policy. Under such circumstances, and assuming that a country can either implement a unilateral permit policy herself or bear the consequences of an internationally coordinated policy, a net creditor country like the European Union might prefer to go ahead alone by implementing a unilateral policy rather than waiting for the other country to agree on an internationally coordinated policy.

\subsection{Comparison of welfare costs of a unilateral foreign and an internationally coordinated permit policy}

Acknowledging that in a dynamically efficient world economy for a net debtor country like the US the welfare costs of a unilateral domestic permit policy are higher than the welfare costs of an internationally coordinated policy, the question remains whether it would be beneficial to agree on an internationally coordinated policy instead of being affected by the unilateral policy to be implemented by the other country. In other words, is there an incentive for a country that has withdrawn from the Kyoto Protocol to agree on an internationally coordinated strategy or is she still better off by non-compliance? Proceeding similarly as before, we gain for the domestic welfare costs of a foreign permit policy:

$$
V\left(S, S^{\star}+\mathrm{d} S^{\star}\right)-V\left(S, S^{\star}\right)=\frac{\mathrm{d} V}{\mathrm{~d} S^{\star}} \mathrm{d} S^{\star}
$$


Comparing (27) and (25), taking account of (22), leads to the following proposition on the difference in the domestic welfare costs of a coordinated permit policy and a foreign unilateral permit policy.

Proposition 4 Let $\alpha_{K}=\alpha_{K}^{\star}, \alpha_{P}=\alpha_{P}^{\star}, \zeta=(1-\zeta), S=S^{*}$. Suppose that either both countries implement a permit policy such that $\mathrm{d} \bar{S}=\delta \mathrm{d} S, \mathrm{~d} \bar{S}^{\star}=(1-\delta) \mathrm{d} S^{\star}$, where $\mathrm{d} S=\mathrm{d} S^{\star}, 0<\delta<1$ and $\delta=1 / 2$ or Foreign implements a permit policy $\mathrm{d} S^{\star}<0$. The difference in domestic welfare costs of a coordinated permit policy and a foreign unilateral permit policy is then given by

$$
\begin{array}{r}
V\left(S+\frac{\mathrm{d} S}{2}, S^{\star}+\frac{\mathrm{d} S^{\star}}{2}\right)-V\left(S, S^{\star}+\mathrm{d} S^{\star}\right)= \\
\frac{1+\beta}{(w-\tau)} \frac{\alpha_{P}}{S}\left\{\left[\gamma-\gamma^{*}\right][i(k+b)+\phi]+\frac{i b}{\left(1-\alpha_{K}\right)}\right\} \frac{\mathrm{d} S^{\star}}{2} .
\end{array}
$$

Depending on the signs of $i$ and $\phi$, three cases emerge:

(i) For $i \geq 0$ (dynamic efficiency) and $\phi>0, \quad V\left(S+\frac{\mathrm{d} S}{2}, S^{\star}+\frac{\mathrm{d} S^{\star}}{2}\right)<V\left(S, S^{\star}+\right.$ $\left.\mathrm{d} S^{\star}\right)$.

(ii) For $i=i^{\star}=0$ (Golden Rule) and $\phi<0, \quad V\left(S+\frac{\mathrm{d} S}{2}, S^{\star}+\frac{\mathrm{d} S^{\star}}{2}\right)<V\left(S, S^{\star}+\right.$ $\left.\mathrm{d} S^{\star}\right)$.

(i) For $i<0$ (dynamic inefficiency), the sign of $V\left(S+\frac{\mathrm{d} S}{2}, S^{\star}+\frac{\mathrm{d} S^{\star}}{2}\right)-V\left(S, S^{\star}+\right.$ $\left.\mathrm{d} S^{\star}\right)$ is ambiguous.

Proof 4 See Proof to Proposition 3.

Under dynamic efficiency (the Golden Rule included) and irrespective of the external balance of a country, the domestic welfare costs of unilateral foreign permit policy are smaller than those of a internationally coordinated permit policy provided that in case of a net foreign creditor the Golden Rule applies. While the other country that is willing to implement a unilateral permit policy always gains in terms of 
welfare costs when Home agrees to a internationally coordinated policy too, Home prefers non-acting to a harmonized policy (cases i and ii of Proposition 4). As a consequence, the diverging positions towards climate policy result and are also perpetuated.

If, in contrast, dynamic inefficiency holds in the initial steady state (case iii), the sign of $V\left(S+\frac{\mathrm{d} S}{2}, S^{\star}+\frac{\mathrm{d} S^{\star}}{2}\right)-V\left(S, S^{\star}+\mathrm{d} S^{\star}\right)$ is ambiguous. Eventually, the unilateral policy by the other country might thus lead to higher domestic welfare losses than a internationally coordinated policy.

\subsection{Policy implications of welfare analysis for climate policy}

In line with the domestic welfare effects of unilateral fiscal policy (Persson, 1985, p. 80), unilateral permit policy leads unambiguously to a domestic welfare loss if the policy implementing country is a net foreign debtor and if the world economy is dynamically efficient. If on the other hand the world economy is dynamically inefficient, the effect on welfare entails both positive and negative terms and hence can either be in total a cost or a gain. Thus, based on domestic welfare costs, a net debtor country is less likely to decide to implement a unilateral permit policy than a net creditor country, and particularly so if the world economy is dynamically efficient. One policy conclusion from this result is that a permit policy entails, from the perspective of the present domestic and foreign generation, a welfare loss in many circumstances - a cost, which has to be balanced by global far-distant benefits from better environmental quality like slowed global warming.

Secondly, comparing the welfare costs of unilateral domestic permit policy and of an internationally coordinated permit policy as specified above we find that under dynamic efficiency of the world economy the welfare costs of infinitesimally small and internationally coordinated climate policies are smaller than the welfare costs of unilateral permit policy if the domestic country is a net foreign debtor. This is 
also true if the domestic country is a net foreign creditor and the world economy finds itself in a Golden Rule situation. Hence, as a policy implication, net foreign debtor countries under dynamic efficiency as well as net foreign creditor countries in a Golden Rule will opt for international coordination of permit policy instead of a unilateral domestic approach. When the economy switches from dynamic efficiency (including the Golden Rule) to dynamic inefficiency, unilateralism might however dominate (in terms of welfare costs) policy coordination.

Thirdly, for a net foreign debtor country under dynamic efficiency as well as for net foreign creditor country in a Golden Rule, climate political inaction of the domestic country is better (in terms of welfare) than agreeing on international policy coordination. The reason in this case is not that there are no welfare costs for the domestic country at all, but that it is cheaper bearing the welfare costs of foreign climate political actionism than agreeing on international policy coordination. Hence, if the foreign country presses ahead with a unilateral permit policy, the best response of the domestic country is to remain inactive. However, it is important to acknowledge that this conclusion presupposes infinitesimal permits reduction and dynamic efficiency (including the Golden Rule). Under dynamic inefficiency, the difference between the welfare costs of a unilateral and internationally coordinated permit policy is in general ambiguous. For some feasible parameter values, the domestic welfare costs of unilateral foreign policy might be higher than those of an internationally coordinated policy.

Taken together, these results imply that whenever a unilateral policy leads to higher domestic welfare costs when the policy is implemented domestically than abroad, it is also true that an internationally coordinated policy causes higher welfare costs than a unilateral policy by the other country. Consequently, if a country has a low inclination to implement a national climate policy in the first place, once the other country has implemented a policy it is still better, in terms of welfare costs, to not agree on an internationally coordinated policy. 


\section{Conclusion}

This paper investigates the effects of unilateral and internationally coordinated climate policies in a two-country, two-good OLG model. After deriving the intertemporal equilibrium dynamics of the terms of trade, Home's and Foreign's capital intensities, we analyze the impact of a unilateral permit reduction on the steady state of the key economic variables. We find that the terms of trade of the policy implementing country improve while capital intensities in both countries fall stronger in the policy implementing country than abroad.

While these steady state effects of unilateral climate policy are independent of the net foreign asset positions of the countries, domestic and foreign welfare show opposing effects. While the terms of trade improvement is welfare enhancing for the policy implementing country and welfare reducing for the other country, the fall in capital intensities cause a declining net wage and an increasing interest rate. In total, for the dynamically efficient case, a permit reduction by a net debtor country is associated with domestic and foreign welfare costs - and this gives an economic explanation why climate policy has been implemented with large hesitation in the past. Moreover, that welfare costs are higher for a net debtor country helps to better understand why the US has withdrawn from the Kyoto Protocol.

This leads to the question whether it is also in the own interest of a country to abstain from unilateral permit policy or to opt-in on an internationally coordinated permit policy that achieves an equal reduction target as each of the unilateral policies. Under dynamic efficiency, a net foreign debtor country reduces its welfare by agreeing to an internationally coordinated permit policy relative to a unilateral foreign policy. The reason is that under international policy coordination with equal reduction targets the terms of trade effect vanishes and that the effect on capital intensities in both countries is less pronounced than of unilateral policies which leads to ameliorated welfare costs. Surprisingly, this result also applies when the country under consideration is a net foreign creditor and the world economy stays in a 
Golden Rule situation.

Under dynamic inefficiency, however, independent of whether the permit reducing country is a net foreign debtor or not, the welfare costs of a unilateral domestic permit policy might be lower than of agreeing to an internationally coordinated policy. This is also true when the foreign country has already, due to whatever reason, reduced emission permits and the domestic country has to choose between two options: remaining inactive by simply bearing the welfare costs of Foreign's climate political actionism might be more costly, in terms of welfare, than opting-in on international policy coordination.

Under dynamic efficiency, however, our dynamic general equilibrium approach for two large economies supplements the reasoning provided by static game game theory and political economics why unilateral climate policy is not in the interest of some highly developed countries even if other countries implement such a policy, or in other words: internationally coordinated climate policies do not represent an option for withdrawers from the Kyoto Protocol, particularly if they are net foreign debtors. This conclusion no longer pertains if the world economy becomes dynamically inefficient.

\section{References}

Bang, Guri, Camilla Bretteville Froyn, Jon Hovi and Fredric C. Menz (2007). The United States and international climate cooperation: international "pull" versus domestic "push". Energy Policy 35, 1282-1291.

Baumol, William J. and Wallace E. Oates (1988). The theory of environmental policy. 2nd ed. Cambridge University Press. Cambridge.

Bréchet, Thierry, Stéphane Lambrecht and Fabien Prieur (2009). Intertemporal transfers of emission quotas in climate policies. Economic Modelling 26, 126-134. 
Copeland, Brian R. and M. Scott Taylor (2005). Free trade and global warming: a trade theory view of the Kyoto Protocol. Journal of Environmental Economics and Management 49, 205-234.

Diamond, Peter (1965). National debt in a neoclassical growth model. American Economic Review 55, 1126-1150.

Farmer, Karl and Birgit Friedl (forthcoming). Public, debt, terms of trade, and welfare in a world economy with external imbalances. In: Public Debt: Issues and Perspectives (F. Columbus, Ed.). Nova Science. Hauppauge, NY.

Farmer, Karl, Birgit Friedl and Andreas Rainer (2008). Effects of unilateral climate policy on terms of trade, capital accumulation, and welfare in a world economy. Working Paper 2375. CESifo. Munich.

Frenkel, Jacob A. and Assif Razin (1986). The international transmission and effects of fiscal policies. American Economic Review 76, 330-335.

Gosh, Atish R. (1992). Fiscal policy, the terms of trade and the external balance. Journal of International Economics 33, 105-25.

Jouvet, Pierre-André, Philippe Michel and Gilles Rotillon (2005a). Equilibrium with a market of permits. Research in Economics 59, 148-163.

Jouvet, Pierre-André, Philippe Michel and Gilles Rotillon (2005b). Optimal growth with pollution: how to use pollution permits? Journal of Economic Dynamics and Control 29(9), 1597-1609.

Lipton, David and Jeffrey Sachs (1983). Accumulation and growth in a two-country model. Journal of International Economics 15(1-2), 135-159.

Meade, James E. (1952). External economies and diseconomies in a competitive situation. Economic Journal LXII, 54-67.

Obstfeld, Maurice (1989). Fiscal deficits and relative prices in a growing world economy. Journal of Monetary Economics 23, 461-84. 
Ono, Tetsuo (2002). The effects of emission permits on growth and the environment. Environmental and Resource Economics 21, 75-87.

Persson, Torsten (1985). Deficits and intergenerational welfare in open economies. Journal of International Economics 19(1-2), 67-84.

Selin, Henrik and Stacy D. VanDeveer (2007). Political science and prediction: What's next for U.S. climate change policy? Review of Political Research 24, 1-27.

Sydsaeter, Knud, Peter Hammond, Able Seierstad and Arne Størm (2005). Further Mathematics for Economic Analysis. Pearson. Essex.

Weber, Christopher L. and Glen P. Peters (2009). Climate change policy and international trade: policy considerations in the US. Energy Policy 37, 432-440.

Zee, Howell H. (1987). Government debt, capital accumulation, and the terms of trade in a model of interdependent economies. Economic Inquiry 25, 599-618.

\section{A Appendix}

\section{A.1 Existence of steady states}

This section is devoted to show how the existence of at least two non-trivial steady state solutions of the intertemporal equilibrium dynamics (16)-(15) can be proven. To this end, rewrite first equations (17)-(19) as follows:

$$
\begin{aligned}
k^{*} & =\tilde{S} k^{\epsilon} \quad \text { where } \quad \tilde{S} \equiv\left[\frac{\alpha_{K}^{*}}{\alpha_{K}}\left(\frac{S^{*}}{S}\right)^{\alpha_{P}}\right]^{\frac{1}{1-\alpha_{K}^{*}}}, \\
h & =\frac{\zeta}{1-\zeta} \frac{k^{*}}{k}\left[1+\left(1-\frac{\alpha_{K}}{\alpha_{K}^{*}}\right) \frac{M S^{\alpha_{P}} k^{\alpha_{K}-1}}{1-M S^{\alpha_{P}} k^{\alpha_{K}-1}}\right], \\
k & =\bar{F}(k)+\Delta(k) .
\end{aligned}
$$


whereby

$$
\begin{aligned}
\bar{F}(k) & =\left(1-\tilde{\alpha}_{K}\right) \sigma \frac{(1+i)}{\alpha_{K}}-\vartheta(k)(1+i)-\vartheta(k)(1-\sigma), \\
\Delta(k) & =-\zeta\left(1-\frac{\alpha_{K}}{\alpha_{K}^{*}}\right) \frac{x}{1-\frac{(1+i)}{\alpha_{K}}} \phi
\end{aligned}
$$

with $\left(1-\tilde{\alpha}_{K}\right) \equiv \zeta\left(1-\alpha_{K}\right)+(1-\zeta)\left(1-\alpha_{K}^{*}\right) \frac{\alpha_{K}}{\alpha_{K}^{*}}$ and $\vartheta(k) \equiv \zeta b+(1-\zeta) b^{*} \frac{k}{k^{*}}$.

Next, consider the case of identical production technologies, i.e. $\alpha_{K}=\alpha_{K}^{*}$. Clearly, $\Delta(k)=0$ and $(31)$ reduces to

$$
k=F(k) \equiv\left(1-\alpha_{K}\right) \sigma \frac{(1+i)}{\alpha_{K}}-\vartheta \sigma(1+i)-\vartheta(1-\sigma),
$$

with $\vartheta \equiv\left(\zeta b+(1-\zeta) b^{*} \widetilde{S}^{-1}\right)$. Proposition 1 from Farmer et al. (2008, 10-11), which is reproduced as Lemma below, provides sufficient conditions for exactly two strictly positive solutions of equation $k=F(k)$.

Proposition 5 Let the parameter vector $\omega=\left(\alpha_{K}, \alpha_{P}, \beta, \zeta, M, S, \vartheta\right)$ be an element of the parameter space $\Omega=[0,1]^{4} \times \mathbb{R}_{+}^{3}$. For any $\omega \in \Omega$ there exists $\bar{\vartheta} \in \mathbb{R}_{++}$such that

1. for $\vartheta<\bar{\vartheta}$ there are one trivial $(k=0)$ and two non-trivial steady states $k^{L}$ and $k^{H}$ with $0<k^{L}<k^{H}<\bar{k}$,

2. for $\vartheta=\bar{\vartheta}$ there are one trivial and one non-trivial steady state, and

3. for $\vartheta>\bar{\vartheta}$ there is only the trivial steady state.

Proof 5 see Appendix A.1 in Farmer et al. (2008).

The next step is to prove the existence of at least two strictly positive solutions of the equation $k=\bar{F}(k)+\Delta(k)$. The central insight here is that $\bar{F}(k)+\Delta(k)$ depends continuously on $\alpha_{K}^{*}$. 
Proposition 6 For every parameter set $\omega=\left(\alpha_{K}, \alpha_{K}^{*}, \alpha_{P}, \beta, \zeta, M, S, b, b^{*}\right) \in \Omega=$ $[0,1]^{5} \times \mathbb{R}_{+}^{4}$ with $\left|\alpha_{K}-\alpha_{K}^{*}\right|$ sufficiently small some (non-unique) $\bar{b}, \bar{b}^{*}>0$ exist such that for all $b \in(0, \bar{b})$ and $b^{*} \in\left(0, \bar{b}^{*}\right)$ there are at least two non-trivial steady state solutions $\left(h, k, k^{*}\right)$.

Proof 6 For $\alpha_{K}=\alpha_{K}^{*}$ we know from Lemma 5 that for all $\vartheta<\bar{\vartheta}$ exactly two solutions $0<k^{L}<k^{H}$ of $k=\bar{F}(k)+\Delta(k)$ occur. Since $\bar{F}(k)+\Delta(k)$ depends continuously on $\alpha^{*}$, there is some interval $\Lambda=\left(\alpha_{-}, \alpha_{+}\right)$such that for all $\alpha_{K}^{*} \in \Lambda$ at least two distinct solutions $0<\tilde{k}^{L}<\tilde{k}^{H}$ exist ${ }^{8}$.

\section{A.2 Saddle-path stability of steady states}

To prove the dynamic stability of a non-trivial steady state solution, we consider the Jacobian of the dynamic system (16)-(15) in a small neighborhood around both non-trivial steady state solutions. Again, we focus first on the case of identical production elasticities of capital. Proposition 2 from Farmer et al. $(2008,12)$ claims that for $\vartheta<\bar{\vartheta}$, at the lower steady state solution, $k^{L}$, two eigenvalues of the Jacobian are larger than one and one eigenvalue equals $\alpha_{K}<1$, while at the larger steady state solution of $k=F(k)$ two eigenvalues are less than one and one eigenvalue is larger than one. Hence, the lower steady state is saddle-path unstable while the larger steady state is saddle-path stable.

In considering the general case $\alpha_{K} \neq \alpha_{K}^{*}$, we focus again at a sufficiently small difference between $\alpha_{K}$ and $\alpha_{K}^{*}$. Under this assumption, Proposition 2 of Farmer et al. $(2008,12)$ can be generalized as the following Proposition 7.

Proposition 7 For every parameter set $\omega \in \Omega$ with $\left|\alpha_{K}-\alpha_{K}^{*}\right|$ sufficiently small some (non-unique) $\bar{b}, \bar{b}^{*}>0$ exist such that for all $b \in(0, \bar{b})$ and $b^{*} \in\left(0, \bar{b}^{*}\right)$ the larger strictly positive solution of $k=\bar{F}(k)+\Delta(k)$ is saddle-path stable.

\footnotetext{
${ }^{8}$ The analysis of $\bar{F}(k)+\Delta(k)$ shows, however, that for $\alpha_{K}<\alpha_{K}^{*}$ a third steady state $k>k^{H}$ exists.
} 
Proof 7 For $\alpha_{K}=\alpha_{K}^{*}$, see the proof to Proposition 2 of Farmer et al. (2008, 2931). Again, since $k=\bar{F}(k)+\Delta(k)$ depends continuously on $\alpha^{*}$, there is some interval $\Lambda_{1}=\left(\alpha_{-}^{1}, \alpha_{+}^{1}\right)$ such that for all $\alpha_{K}^{*} \in \Lambda_{1} \subset \Lambda$ the larger solution $k^{H}$ of $k=\bar{F}(k)+\Delta(k)$ is saddle-path stable.

\section{A.3 Proof of Proposition 1}

To determine the effects of a marginal unilateral reduction of emission permits on the three dynamic variables, we totally differentiate (17), (18), and (19), with respect to $S$ and $S^{*}$. This yields:

$$
\left[\begin{array}{ccc}
0 & -\epsilon\left(\frac{k^{*}}{k}\right) & 1 \\
\phi & h \frac{\partial \phi}{\partial k} & \frac{\partial \phi^{*}}{\partial k^{*}} \\
(1-\zeta) H & (1-\zeta) h \frac{\partial H}{\partial k} & -\zeta \frac{\partial H^{*}}{\partial k^{*}}
\end{array}\right]\left[\begin{array}{c}
\mathrm{d} h \\
\mathrm{~d} k \\
\mathrm{~d} k^{*}
\end{array}\right]=\left[\begin{array}{c}
-\frac{\alpha_{P}}{1-\alpha_{K}^{*}} \frac{k^{*}}{S} \\
-h \frac{\partial \phi}{\partial S} \\
-(1-\zeta) h \frac{\partial H}{\partial S}
\end{array}\right] \mathrm{d} S+\left[\begin{array}{c}
\frac{\alpha_{P}^{*}}{1-\alpha_{K}^{*}} \frac{k^{*}}{S^{*}} \\
-\frac{\partial \phi^{*}}{\partial S^{*}} \\
\zeta \frac{\partial H^{*}}{\partial S^{*}}
\end{array}\right] \mathrm{d} S^{*}
$$

After defining the slopes of the $K K$ - and $G G$-curve curve at the steady state by

$$
\left.\frac{\mathrm{d} h}{\mathrm{~d} k}\right|_{\mid K K}=-\frac{\left[h \frac{\partial \phi}{\partial k}+\frac{\partial \phi^{*}}{\partial k^{*}} \frac{\partial k^{*}}{\partial k}\right]}{\phi},\left.\quad \frac{\mathrm{d} h}{\mathrm{~d} k}\right|_{G G}=\frac{-(1-\zeta) h \frac{\partial H}{\partial k}+\zeta \frac{\partial H^{*}}{\partial k^{*}} \frac{\partial k^{*}}{\partial k}}{(1-\zeta) H}
$$

and the shift of these curves caused by a change in $S$ and $S^{*}$ by

$$
\begin{gathered}
\left.\frac{\partial h}{\partial S}\right|_{\mid K K}=-\frac{\left[h \frac{\partial \phi}{\partial S}+\frac{\partial \phi^{*}}{\partial k^{*}} \frac{\partial k^{*}}{\partial S}\right]}{\phi},\left.\quad \frac{\partial h}{\partial S}\right|_{\mid G G}=\frac{-(1-\zeta) h \frac{\partial H}{\partial S}+\zeta \frac{\partial H^{*}}{\partial k^{*}} \frac{\partial k^{*}}{\partial S}}{(1-\zeta) H}, \\
\frac{\partial h}{\partial S^{*} \mid K K}=-\frac{\left[\frac{\partial \phi^{*}}{\partial k^{*}} \frac{\partial k^{*}}{\partial S^{*}}+\frac{\partial \phi^{*}}{\partial S^{*}}\right]}{\phi}, \quad \frac{\partial h}{\partial S^{*} \mid G G}=\frac{\zeta\left[\frac{\partial H^{*}}{\partial S^{*}}+\frac{\partial H^{*}}{\partial k^{*}} \frac{\partial k^{*}}{\partial S^{*}}\right]}{(1-\zeta) H}
\end{gathered}
$$

the solution of (32) by using Cramer's rule reads as follows:

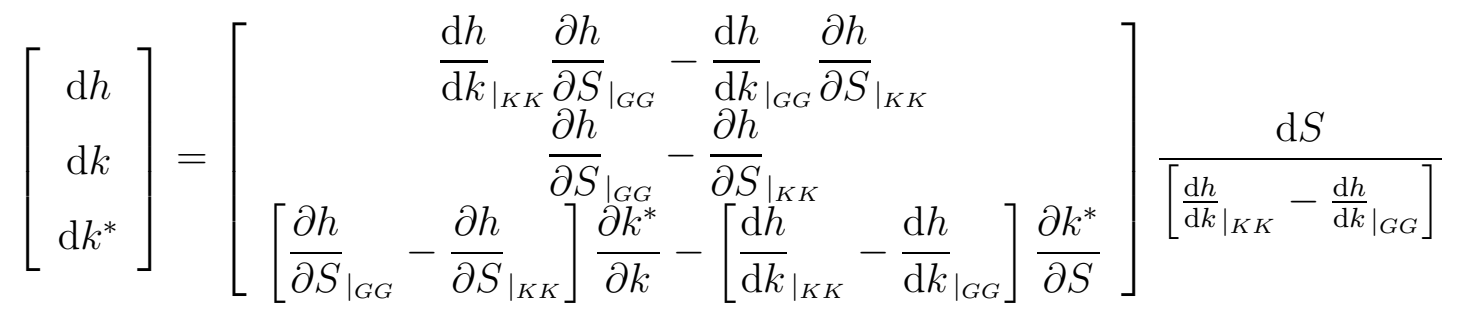




$$
\left[\begin{array}{c}
\mathrm{d} h \\
\mathrm{~d} k \\
\mathrm{~d} k^{*}
\end{array}\right]=\left[\begin{array}{c}
\left.\frac{\mathrm{d} h}{\mathrm{~d} k}\right|_{K K} \frac{\partial h}{\left.\partial S^{*}\right|_{G G}}-\left.\frac{\mathrm{d} h}{\mathrm{~d} k}\right|_{G G} \frac{\partial h}{\left.\partial S^{*}\right|_{K K}} \\
\frac{\left.\frac{\partial h}{\partial S^{*}}\right|_{G G}}{\left.\partial S^{*}\right|_{K K}} \\
{\left[\frac{\partial h}{\left.\partial S^{*}\right|_{G G}}-\frac{\partial h}{\left.\partial S^{*}\right|_{K K}}\right]_{\frac{\partial k^{*}}{\partial k}}-\left[\left.\frac{\mathrm{d} h}{\mathrm{~d} k}\right|_{\left.\right|_{K K}}+\left.\frac{\mathrm{d} h}{\mathrm{~d} k}\right|_{G G}\right] \frac{\partial k^{*}}{\partial S^{*}}}
\end{array}\right] \frac{\mathrm{d} S^{*}}{\left[\left.\frac{\mathrm{d} h}{\mathrm{~d} k}\right|_{K K}-\left.\frac{\mathrm{d} h}{\mathrm{~d} k}\right|_{G G}\right]}
$$

To show that $\mathrm{d} h / \mathrm{d} S=-\alpha_{P} h /\left[S\left(1-\alpha_{K}\right)\right]$, we proceed in two steps. First, we show that $\alpha_{K}=\alpha_{K}^{*}$ and $\alpha_{P}=\alpha_{P}^{*}$ implies that $\mathrm{d} h / \mathrm{d} k_{\left.\right|_{G G}}=0$. From (33) we know that $\mathrm{d} h / \mathrm{d} k_{\left.\right|_{G G}}=\left[-(1-\zeta) h \partial H / \partial k+\zeta \partial H^{*} / \partial k^{*} \partial k^{*} / \partial k\right] /[(1-\zeta) H]$. Acknowledging the definition $H=M S^{\alpha_{P}} k^{\alpha_{K}}-k, \partial H / \partial k=1+i-1=i$ follows. Analogously, $\partial H^{*} / \partial k^{*}=1+i^{*}-1=i^{*}$ holds, and hence $\mathrm{d} h / \mathrm{d} k_{\left.\right|_{G G}}=$ $\left[-(1-\zeta) h i+\zeta i^{*} \epsilon\left(k^{*} / k\right)\right] /[(1-\zeta) H]$. Since $i^{*}=i, \epsilon=1, k^{*}=\tilde{S} k$ and $h=$

$\zeta /(1-\zeta) \tilde{S}, \mathrm{~d} h / \mathrm{d} k_{\left.\right|_{G G}}=0$ follows. Second, $\mathrm{d} h / \mathrm{d} k_{\left.\right|_{G G}}=0$ implies that $\mathrm{d} h / \mathrm{d} S=$ $\partial h / \partial S_{\left.\right|_{G G}}=\left[-(1-\zeta) h \partial H / \partial S+\zeta \partial H^{*} / \partial k^{*} \partial k^{*} / \partial S\right] /[(1-\zeta) H]$. Since $\partial H / \partial S=$ $\alpha_{P} / \alpha_{K}(1+i) k / S$, and again using $h=\zeta /(1-\zeta) \tilde{S}, \mathrm{~d} h / \mathrm{d} S=\partial h / \partial S_{\left.\right|_{G G}}=-\alpha_{P} /(1-$ $\left.\alpha_{K}\right) h / S$. Applying a similar argument to derive the other differentials, and acknowledging that for $\alpha_{K}=\alpha_{K}^{*}$ and $\alpha_{P}=\alpha_{P}^{*}(17)-(19)$ reduce to $k+\vartheta(1-\sigma)=$ $\sigma(1+i) / \alpha_{K}\left[\left(1-\alpha_{K}\right) k-\alpha_{K} \vartheta\right]$ brings forth the stated result.

\section{A.4 Proof of Proposition 2}

To derive (22)-(23), note that $\alpha_{K}=\alpha_{K}^{*}$ and $\alpha_{P}=\alpha_{P}^{*}$ implies that $k+\vartheta(1-\sigma)=$ $\sigma(1+i) /\left(\alpha_{K}\right)\left[\left(1-\alpha_{K}\right) k-\alpha_{K} \vartheta\right]$. Furthermore, $(w-\tau)=\left(1-\alpha_{K}\right) / \alpha_{K}(1+i) k-i b$ and $\phi=k+b-s$, and hence

$$
\begin{aligned}
& {\left[\frac{\partial(w-\tau)}{\partial k}+\frac{s}{(1+i)} \frac{\partial(1+i)}{\partial k}\right]=\frac{\left(1-\alpha_{K}\right)}{k}[i(k+b)+\phi],} \\
& {\left[\frac{\partial(w-\tau)}{\partial S}+\frac{s}{(1+i)} \frac{\partial(1+i)}{\partial S}\right]=\frac{\alpha_{P}}{S}(w-\tau-b+s) .}
\end{aligned}
$$

To sign (22), acknowledge that $\mathrm{d} V / \mathrm{d} S>0$ is certainly positive if $\phi>0$ and $i \geq 0$. If $\phi<0$ and $i=0$ (Golden Rule), $\mathrm{d} V / \mathrm{d} S>0$ if $\gamma \phi+\zeta k / \alpha_{K}>0$. In all other cases, both positive and negative terms prevail, and thus $\mathrm{d} V / \mathrm{d} S$ is ambiguous. For (23), a similar argument applies, the specific conditions are summarized in Proposition 2. 


\section{CESifo Working Paper Series}

for full list see www.cesifo-group.org/wp

(address: Poschingerstr. 5, 81679 Munich, Germany, office@cesifo.de)

2701 Felix Bierbrauer, Optimal Income Taxation and Public Goods Provision in a Large Economy with Aggregate Uncertainty, July 2009

2702 Marc Gronwald, Investigating the U.S. Oil-Macroeconomy Nexus using Rolling Impulse Responses, July 2009

2703 Ali Bayar and Bram Smeets, Government Deficits in the European Union: An Analysis of Entry and Exit Dynamics, July 2009

2704 Stergios Skaperdas, The Costs of Organized Violence: A Review of the Evidence, July 2009

2705 António Afonso and Christophe Rault, Spend-and-tax: A Panel Data Investigation for the EU, July 2009

2706 Bruno S. Frey, Punishment - and beyond, July 2009

2707 Michael Melvin and Mark P. Taylor, The Crisis in the Foreign Exchange Market, July 2009

2708 Firouz Gahvari, Friedman Rule in a Model with Endogenous Growth and Cash-inadvance Constraint, July 2009

2709 Jon H. Fiva and Gisle James Natvik, Do Re-election Probabilities Influence Public Investment?, July 2009

2710 Jarko Fidrmuc and Iikka Korhonen, The Impact of the Global Financial Crisis on Business Cycles in Asian Emerging Economies, July 2009

2711 J. Atsu Amegashie, Incomplete Property Rights and Overinvestment, July 2009

2712 Frank R. Lichtenberg, Response to Baker and Fugh-Berman's Critique of my Paper, "Why has Longevity Increased more in some States than in others?", July 2009

2713 Hans Jarle Kind, Tore Nilssen and Lars Sørgard, Business Models for Media Firms: Does Competition Matter for how they Raise Revenue?, July 2009

2714 Beatrix Brügger, Rafael Lalive and Josef Zweimüller, Does Culture Affect Unemployment? Evidence from the Röstigraben, July 2009

2715 Oliver Falck, Michael Fritsch and Stephan Heblich, Bohemians, Human Capital, and Regional Economic Growth, July 2009 
2716 Wladimir Raymond, Pierre Mohnen, Franz Palm and Sybrand Schim van der Loeff, Innovative Sales, R\&D and Total Innovation Expenditures: Panel Evidence on their Dynamics, July 2009

2717 Ben J. Heijdra and Jochen O. Mierau, Annuity Market Imperfection, Retirement and Economic Growth, July 2009

2718 Kai Carstensen, Oliver Hülsewig and Timo Wollmershäuser, Price Dispersion in the Euro Area: The Case of a Symmetric Oil Price Shock, July 2009

2719 Katri Kosonen and Gaëtan Nicodème, The Role of Fiscal Instruments in Environmental Policy, July 2009

2720 Guglielmo Maria Caporale, Luca Onorante and Paolo Paesani, Inflation and Inflation Uncertainty in the Euro Area, July 2009

2721 Thushyanthan Baskaran and Lars P. Feld, Fiscal Decentralization and Economic Growth in OECD Countries: Is there a Relationship?, July 2009

2722 Nadia Fiorino and Roberto Ricciuti, Interest Groups and Government Spending in Italy, 1876-1913, July 2009

2723 Andreas Wagener, Tax Competition, Relative Performance and Policy Imitation, July 2009

2724 Hans Fehr and Fabian Kindermann, Pension Funding and Individual Accounts in Economies with Life-cyclers and Myopes, July 2009

2725 Ernesto Reuben and Arno Riedl, Enforcement of Contribution Norms in Public Good Games with Heterogeneous Populations, July 2009

2726 Kurt Schmidheiny and Marius Brülhart, On the Equivalence of Location Choice Models: Conditional Logit, Nested Logit and Poisson, July 2009

2727 Bruno S. Frey, A Multiplicity of Approaches to Institutional Analysis. Applications to the Government and the Arts, July 2009

2728 Giovanni Villani, A Strategic R\&D Investment with Flexible Development Time in Real Option Game Analysis, July 2009

2729 Luca Di Corato and Michele Moretto, Investing in Biogas: Timing, Technological Choice and the Value of Flexibility from Inputs Mix, July 2009

2730 Gilad D. Aharonovitz, Nathan Skuza and Faysal Fahs, Can Integrity Replace Institutions? Theory and Evidence, July 2009

2731 Michele Moretto and Sergio Vergalli, Managing Migration through Conflicting Policies: an Option-theory Perspective, July 2009

2732 Volker Nitsch, Fly or Cry: Is Airport Noise Costly?, July 2009 
2733 Francesco Cinnirella and Joachim Winter, Size Matters! Body Height and Labor Market Discrimination: A Cross-European Analysis, July 2009

2734 Samuel Bowles and Sandra Polanía Reyes, Economic Incentives and Social Preferences: A Preference-based Lucas Critique of Public Policy, July 2009

2735 Gary Burtless, Lessons of the Financial Crisis for the Design of National Pension Systems, July 2009

2736 Helmuth Cremer, Firouz Gahvari and Pierre Pestieau, Fertility, Human Capital Accumulation, and the Pension System, July 2009

2737 Hans Jarle Kind and Frank Stähler, Market Shares in Two-Sided Media Industries, July 2009

2738 Pamela Campa, Alessandra Casarico and Paola Profeta, Gender Culture and Gender Gap in Employment, August 2009

2739 Sebastian Gechert, Supplementary Private Health Insurance in Selected Countries: Lessons for EU Governments?, August 2009

2740 Leif Danziger, Endogenous Monopsony and the Perverse Effect of the Minimum Wage in Small Firms, August 2009

2741 Yan Dong and John Whalley, A Third Benefit of Joint Non-OPEC Carbon Taxes: Transferring OPEC Monopoly Rent, August 2009

2742 Valentina Bosetti, Carlo Carraro and Massimo Tavoni, Climate Change Mitigation Strategies in Fast-Growing Countries: The Benefits of Early Action, August 2009

2743 Christina Felfe, The Willingness to Pay for Job Amenities: Evidence from Mothers' Return to Work, August 2009

2744 Jörg Franke, Christian Kanzow, Wolfgang Leininger and Alexandra Väth, Effort Maximization in Asymmetric N-Person Contest Games, August 2009

2745 Bruno S. Frey and Paolo Pamini, Making World Heritage Truly Global: The Culture Certificate Scheme, August 2009

2746 Frank N. Caliendo, Is Social Security behind the Collapse of Personal Saving?, August 2009

2747 Caterina Liesegang and Marco Runkel, Corporate Income Taxation of Multinationals and Fiscal Equalization, August 2009

2748 Chrysovalantou Milliou and Apostolis Pavlou, Upstream Horizontal Mergers and Efficiency Gains, August 2009

2749 Rüdiger Pethig and Christian Wittlich, Interaction of Carbon Reduction and Green Energy Promotion in a Small Fossil-Fuel Importing Economy, August 2009 
2750 Kai Carstensen, Oliver Hülsewig and Timo Wollmershäuser, Monetary Policy Transmission and House Prices: European Cross-country Evidence, August 2009

2751 Olaf Posch, Explaining Output Volatility: The Case of Taxation, August 2009

2752 Beatrice Scheubel, Daniel Schunk and Joachim Winter, Don't Raise the Retirement Age! An Experiment on Opposition to Pension Reforms and East-West Differences in Germany, August 2009

2753 Daniel G. Arce, Dan Kovenock and Brian Roberson, Suicide Terrorism and the Weakest Link, August 2009

2754 Mario Larch and Wolfgang Lechthaler, Comparative Advantage and Skill-Specific Unemployment, August 2009

2755 Horst Raff and Nicolas Schmitt, Buyer Power in International Markets, August 2009

2756 Seppo Kari, Hanna Karikallio and Jukka Pirttilä, The Impact of Dividend Taxation on Dividends and Investment: New Evidence Based on a Natural Experiment, August 2009

2757 Mirco Tonin and Michael Vlassopoulos, Disentangling the Sources of Pro-social Behavior in the Workplace: A Field Experiment, August 2009

2758 Nicole Grunewald and Inmaculada Martínez-Zarzoso, Driving Factors of Carbon Dioxide Emissions and the Impact from Kyoto Protocol, August 2009

2759 Yu-Fu Chen and Michael Funke, Booms, Recessions and Financial Turmoil: A Fresh Look at Investment Decisions under Cyclical Uncertainty, August 2009

2760 Jan-Egbert Sturm and Jakob de Haan, Does Central Bank Communication really Lead to better Forecasts of Policy Decisions? New Evidence Based on a Taylor Rule Model for the ECB, August 2009

2761 Larry Karp, Sacrifice, Discounting and Climate Policy: Five Questions, August 2009

2762 Marianna Belloc and Samuel Bowles, International Trade, Factor Mobility and the Persistence of Cultural-Institutional Diversity, August 2009

2763 Charles Noussair and Fangfang Tan, Voting on Punishment Systems within a Heterogeneous Group, August 2009

2764 Birgit Bednar-Friedl and Karl Farmer, Internationally Coordinated Emission Permit Policies: An Option for Withdrawers from the Kyoto Protocol?, August 2009 